\title{
Rendimento do arroz e manejo da irrigação e da palha de azevém no sistema mix de pré-germinado ${ }^{1}$
}

\author{
Rice yield and management of irrigation and ryegrass straw on \\ flooded rice in no tillage and water seed system
}

\author{
Eduardo González Pinto ${ }^{2}$ Afranio Almir Righes ${ }^{3}$ Enio Marchezan $^{4}$
}

\section{RESUMO}

\begin{abstract}
A incidencia de arroz vermelho na cultura do arroz irrigado tem praticamente inviabilizado o cultivo em muitas áreas do Rio Grande do Sul, destacando-se como um dos principais entraves ao aumento da produtividade. Uma alternativa para minimizar o problema é o sistema mix de prégerminado, que consiste em utilizar sementes pré-germinadas, em área com vegetação dessecada e previamente inundada. O sistema apresenta vantagens técnicas e econômicas na cadeia de produção. Entretanto, a decomposição anaeróbia da palha presente na área, após o alagamento, pode provocar a formação de substâncias tóxicas afetando o estabelecimento das plântulas. Este trabalho teve como objetivo determinar o efeito do manejo da água de irrigação e das quantidades de palha de azevém no rendimento de grãos e componentes de produção do arroz irrigado no sistema mix de pré-germinado. $O$ experimento foi conduzido em casa de vegetação, no ano agrícola 1998/99, em PLANOSSOLO HIDROMÓRFICO Eutrófico arênico, pertencente à unidade de mapeamento Vacacai, na Universidade Federal de Santa Maria, em Santa Maria. - RS, utilizando-se a cultivar IRGA 417, em resteva de azevém. Os tratamentos foram avaliados em delineamento inteiramente casualizado, no arranjo fatorial (3x3), com dois fatores: (i) manejo da água em três níveis (lâmina estagnada, com drenagem e com fluxo de superficie) e (ii) palha de azevém em três quantidades $\left(0,00 t h a^{-1}, 3,43 t h a^{-1}\right.$ e 6,86 $\left.t h a^{-1}\right)$. Os resultados evidenciam que, no sistema mix de pré-germinado, mantendo-se uma lâmina estagnada sobre o solo, reduz-se a massa seca total e o rendimento de grãos de arroz em relação ao manejo da água com drenagem e com fluxo de superfície.
\end{abstract}

O aumento na quantidade de palha de azevém na cultura do arroz no sistema de cultivo mix de pré-germinado, sem fluxo de água em superfície ou drenagem, reduz o rendimento de grãos.

Palavras-chave: água, sistema de cultivo, drenagem.

\section{ABSTRACT}

The incidence of red rice on flooded rice production is a limiting factor in many agricultural areas, when high productivity is the objective. Alternative system of crop cultivation using no tillage on flooded water seed system can be used to minimize the problem. Although this system has technical and economical advantages on the production chain, especially on red rice control, anaerobic process of ryegrass straw decomposition may produce toxic substances to rice plants establishment. The objective of this work was to evaluate the effect of different water irrigation management and the amount of ryegrass straw on grain yield and yield components on paddy rice cultivated. The experiment was conducted in greenhouse, during the 1998/99 crop growing season, on Hidromorphy Planosoil, sandy Eutrophic, soil mapping unit "Vacacai", over ryegrass crop residue at the Federal University of Santa Maria, Santa Maria, RS. The rice cultivar IRGA 417 was used. A completely randomized design factorial (3x3), three water management (with neither vertical nor surface in-out water flow over the soil, with drainage and surface water flow) and three amount of ryegrass straw $\left(0.0 t \mathrm{ha}^{-1}, 3.43 \mathrm{tha^{-1 }}\right.$ and 6.86 $\left.t h \mathrm{a}^{-1}\right)$. The data demonstrated that a permanent flooding with neither vertical nor surface in-out water flow reduce dry matter

\footnotetext{
${ }^{1}$ Parte da Dissertação de Mestrado em Engenharia Agrícola apresentada pelo primeiro autor no programa de Pós-graduação em Engenharia Agrícola da Universidade Federal de Santa Maria (UFSM).

${ }^{2}$ Engenheiro Agrônomo, Mestre em Engenharia Agrícola.

${ }^{3}$ Engenheiro Agrônomo, PhD., Professor Titular do Departamento Engenharia Rural, UFSM, 97105-900, Sana Maria, RS. E-mail: righes@ccr.ufsm.br Autor para correspondência.

${ }^{4}$ Engenheiro Agrônomo, Doutor, Professor Titular, Departamento de Fitotecnia, UFSM.
} 
above ground and grain yield when compared to the treatments with drainage and surface in-out water flow. Increasing the amount of ryegrass straw on the no-tillage water seed system, with neither vertical nor surface in-out water flow, on the flooded water the grain yield is reduced.

Key words: water, crop system, drainage, grain yield.

\section{INTRODUÇÃO}

O arroz é cultivado em praticamente todo o mundo e a previsão de produção mundial para a colheita 2000/2001 situa-se ao redor de 591 milhões de toneladas (AGRINUAL, 2001). Segundo a mesma fonte, no ano agrícola 1999/00, o Brasil produziu 9,5 milhões de toneladas de arroz em casca. A incidência de arroz vermelho tem praticamente inviabilizado o cultivo em muitas áreas do Rio Grande do Sul, destacando-se como um dos principais problemas da lavoura orizícola. Uma alternativa pouco conhecida, mas com potencial para minimizar o problema é o cultivo de arroz irrigado no sistema mix de pré-germinado, que consiste em utilizar sementes pré-germinadas, em área com vegetação dessecada e previamente inundada. No entanto, a decomposição anaeróbia da palha presente na área pode provocar a formação de substâncias tóxicas afetando o estabelecimento das plântulas. Segundo PONNAMPERUMA (1965), produtos da redução orgânica podem prejudicar as raízes do arroz por consumir o oxigênio e, também, diretamente, pela intoxicação da planta. Em função do tempo de alagamento, o potencial redox do solo passa de positivo para valores negativos. HITE \& CHENG (1996) citam que o potencial redox é tamponado pela redução de óxidos de ferro e é mantido na faixa de $+100 \mathrm{a}+200 \mathrm{mV}$. Esse tamponamento previne a formação do gás sulfídrico e metano, normalmente encontrado em ambientes alagados. De acordo com CANNELL \& LYNCH (1984), a decomposição de resíduos orgânicos sob condições anaeróbias forma substâncias tóxicas, podendo reduzir o número de plantas emergidas e afetar o crescimento das mesmas. Concentrações muito baixas de ácidos alifáticos são citadas como causadoras da morte de plantas (WATANABE, 1984).

A manutenção da inundação na cultura do arroz é imprescindível para obtenção de altos rendimentos de grãos principalmente durante a fase reprodutiva (STONE et al., 1990; FORNASIERI FILHO \& FORNASIERI, 1993). Segundo PANDE \& MITTRA (1970) e DOTTO et al. (1990), a inundação contínua propicia maior rendimento de grãos, devido à maior a absorção de nutrientes e ao controle de plantas daninhas, porém é menos eficiente no uso da água quando comparado com a irrigação por inundação intermitente (BARRETO \& ROJAS, 1987).
O presente trabalho, teve como objetivo determinar o efeito da quantidade de palha de azevém e o manejo da água de irrigação no rendimento de grãos e componentes do rendimento do arroz, no sistema mix de pré-germinado.

\section{MATERIAL E MÉTODOS}

O experimento foi conduzido em casa de vegetação, no ano agrícola de 1998/99, na Universidade Federal de Santa Maria, Santa Maria, Rio Grande do Sul, localizada na Depressão Central, cujas coordenadas geográficas são $29^{\circ} 41^{\prime} 24^{\prime \prime}$ de latitude sul e 53 48' 42" de longitude oeste e altitude de $95 \mathrm{~m}$. O solo é classificado como PLANOSSOLO HIDROMÓFICO Eutrófico arênico, pertencente à unidade de mapeamento Vacacaí (STRECK et al., 1999).

Os tratamentos avaliados corresponderam a três níveis de manejo da água de irrigação: (i) lâmina estagnada (o nível da água nas caixas foi mantido constante com uma lâmina de $5 \mathrm{~cm}$ ); (ii) com drenagem (manteve-se uma lâmina de água sobre a superfície do solo e simulou-se um fluxo de drenagem equivalente à percolação média de $1,3 \mathrm{~L} \mathrm{dia}^{-1}$, correspondendo a uma lâmina de $10 \mathrm{~mm} \mathrm{dia}^{-1}$ ); (iii) com fluxo de superfície (manteve-se uma lâmina de água sobre a superfície do solo e simulou-se um fluxo de superfície equivalente ao valor médio de $1,3 \mathrm{~L} \mathrm{dia}^{-1}$ ). Para o fator palha de azevém, utilizaram-se três níveis: $0,00 \mathrm{tha}^{-1} ; 3,43 \mathrm{tha}^{-1} \mathrm{e}$ $6,86 \mathrm{tha}^{-1}$. O delineamento experimental foi inteiramente casualizado, no arranjo fatorial $3 \times 3$, com nove tratamentos e quatro repetições, totalizando 36 unidades experimentais. As unidades experimentais constituíram-se de 36 caixas de material plástico com capacidade de 26 litros, $(22,5 \mathrm{~cm}$ de altura, $33 \mathrm{~cm}$ de largura e $50,5 \mathrm{~cm}$ de comprimento, totalizando $0,1271 \mathrm{~m}^{2}$ por caixa).

No interior das caixas de plástico, foi colocada uma camada de $2 \mathrm{~cm}$ de brita e sobre essa, uma manta de bidim (material sintético comercial) a fim de facilitar a drenagem e evitar o entupimento das mangueiras de polietileno que coletavam o fluxo da água de drenagem. Para o preenchimento das caixas, foram coletados monolitos de solo com estrutura não deformada, já com a cultura de azevém estabelecida. A dessecação da cobertura vegetal foi realizada cinco dias antes da inundação da área com $2,4 \mathrm{~L} \mathrm{ha}^{-1} \mathrm{de}$ glifosate. $\mathrm{O}$ controle e manejo da irrigação foi realizado através de um reservatório em acrílico, com altura regulável e com válvula bóia para manter o nível de água constante, de forma que pelo princípio dos vasos comunicantes, automaticamente mantivesse sobre o solo uma lâmina de $5 \mathrm{~cm}$ de água. A adubação e 
semeadura foram realizadas em 01/12/98 aos 15 dias após a inundação do solo. Aplicaram-se $150 \mathrm{~kg} \mathrm{ha}^{-1} \mathrm{de}$ adubo da formula 05-20-20. A semeadura do arroz foi realizada manualmente sobre a resteva da palha do azevém, dessecada, na densidade de $130 \mathrm{~kg}$ sementes $\mathrm{ha}^{-1}$ correspondendo a 60 sementes pré-germinadas por caixa. A pré-germinação das sementes, consistiu em deixá-las imersas em água por um período de 24 horas, seguida de 36 horas fora d'água à sombra. Ao final desse período, as sementes pré-germinadas encontravam-se com o coleoptilo com cerca de 1 a $2 \mathrm{~mm}$ de comprimento. Utilizou-se a cultivar IRGA 417, com poder germinativo de $83 \%$. No momento da semeadura, reduziu-se a altura da lâmina de água nas caixas para $2 \mathrm{~cm}$ de altura. A adubação nitrogenada em cobertura, na forma de uréia, foi aplicada no início do perfilhamento e por ocasião da iniciação do primórdio floral na dose $25 \mathrm{~kg} \mathrm{ha}^{-1}$ de $\mathrm{N}$ em cada fase. Determinações fenométricas: (i) número de plantas por $\mathrm{m}^{2}$ determinado aos 10 dias após a emergência das plantas; (ii) estatura de plantas obtida através da medição da distância entre o colo da planta até o ápice da panícula, em 10 plantas por repetição, sendo os resultados expressos em centímetros; (iii) número de panículas por planta obtido pela contagem das panículas nas 36 caixas por ocasião da colheita; (iv) número de grãos por panícula obtido através de uma amostra de 10 panículas por repetição, contando-se o número de espiguetas férteis; (v) rendimento de grãos estimado a partir da colheita de todas as plantas que se encontravam na caixa; (vi) massa seca total, obtida somando-se a massa seca de colmos, folhas e a produção de grãos por planta, após secagem em estufa a $65{ }^{\circ} \mathrm{C}$ com circulação forçada de ar, até obtenção de massa constante.

A análise estatística dos dados foi realizada através do programa computacional (SOC-SOFTWARE SCIENTIFIC), desenvolvido pelo Núcleo Tecnológico para Informática - NETIA/EMBRAPA - Campinas, SP e pela Universidade Federal de Santa Maria - CCR/ Departamento de Fitotecnia, RS, usando-se o teste F para a análise da variância para os fatores qualitativos como manejo da água e, a regressão, para o fator palha (quantitativo). As médias dos tratamentos foram comparadas entre si pelo teste de Tukey em nível de $5 \%$ de probabilidade de erro.

\section{RESULTADOS E DISCUSSÃO}

O rendimento de grãos reduziu-se à medida que aumentou a quantidade de palha de azevém, relacionando-se através de uma regressão linear decrescente em função da quantidade de palha de azevém (Figura 1), constando o maior rendimento de grãos no tratamento sem palha, atingindo $6.421 \mathrm{~kg} \mathrm{ha}^{-1}$.

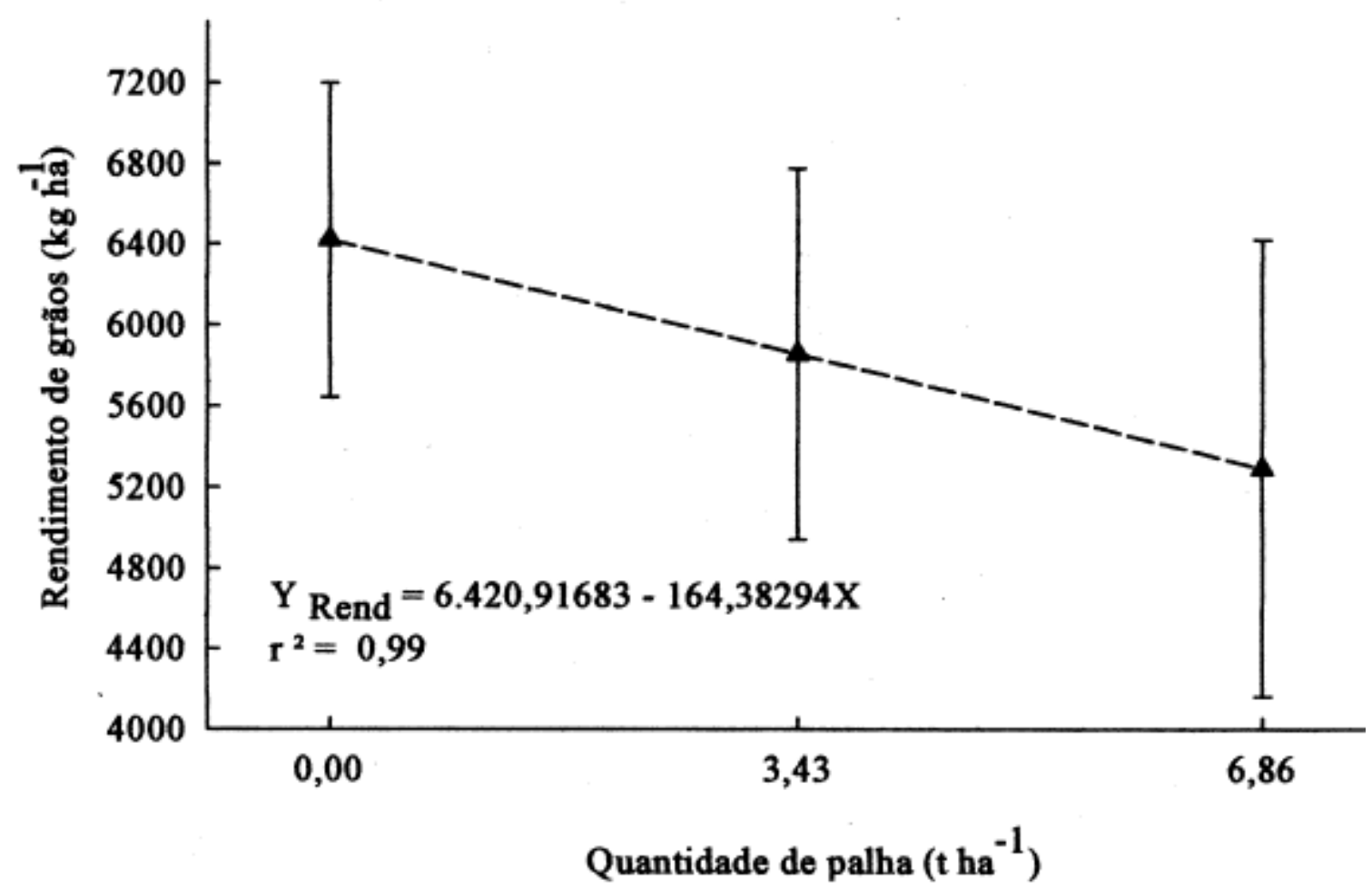

Figura 1 - Rendimento de grãos do arroz “cv. IRGA417”, em kg ha" ${ }^{-1}$, em função das quantidades de palha de azevém no sistema de cultivo mix de pré-germinado. Santa Maria, RS, 2000

Ciência Rural, v. 33, n. 2, mar-abr, 2003. 
Tabela 1 - Média do rendimento de grãos $\left(\mathrm{kg} \mathrm{ha}^{-1}\right)$, panículas por $\mathrm{m}^{-2}$, grãos por panícula, estatura de plantas $(\mathrm{cm})$, plantas por $\mathrm{m}^{2}$ e massa seca total $\left(\mathrm{g} \mathrm{m}^{-2}\right)$, do arroz irrigado em função dos níveis de manejos da água de irrigação no sistema de cultivo mix de prégerminado. Santa Maria, RS, 2000.

\begin{tabular}{|c|c|c|c|c|}
\hline \multirow[b]{2}{*}{ Determinações } & \multicolumn{3}{|c|}{ Níveis de manejo da água de irrigação } & \multirow{2}{*}{$\begin{array}{l}\mathrm{CV}^{1} \\
(\%)\end{array}$} \\
\hline & $\begin{array}{c}\text { Com } \\
\text { drenagem }\end{array}$ & $\begin{array}{c}\text { Com fluxo } \\
\text { de superfície }\end{array}$ & $\begin{array}{c}\text { Com lâmina } \\
\text { estagnada }\end{array}$ & \\
\hline $\begin{array}{l}\text { Rendimento de grãos } \\
\left(\mathrm{kg} \mathrm{ha}^{-1}\right)\end{array}$ & $6.694 a^{*}$ & $6.012 \mathrm{~b}$ & $4.865 \mathrm{c}$ & 9,7 \\
\hline Panículas por $\mathrm{m}^{2}$ & $363 \mathrm{a}$ & $324 b$ & $261 \mathrm{c}$ & 9,6 \\
\hline Grãos por panícula & $76 \mathrm{a}$ & $76 \mathrm{a}$ & $76 \mathrm{a}$ & 2,7 \\
\hline Estatura $(\mathrm{cm})$ & $74 \mathrm{a}$ & $74 \mathrm{a}$ & $74 \mathrm{a}$ & 1,4 \\
\hline Plantas por $\mathrm{m}^{2}$ & $397 \mathrm{a}$ & $364 \mathrm{ab}$ & $324 b$ & 47,7 \\
\hline Massa seca total $\left(\mathrm{g} / \mathrm{m}^{2}\right)$ & $1857 \mathrm{a}$ & $1770 \mathrm{~b}$ & $1499 \mathrm{c}$ & 4,8 \\
\hline
\end{tabular}

* Médias não seguidas com mesma letra minúscula na linha horizontal apresentam diferenças significativa pelo teste de Tukey, em nível de $5 \%$ de probabilidade de erro.

${ }^{1}$ Coeficiente de variação.

Tratamentos com 3,43 e 6,86t ha ${ }^{-1}$ de palha de azevém provocaram reduções no rendimento de grãos de $8,78 \mathrm{e}$ $17,56 \%$ (564 e 1128kg ha ${ }^{-1}$, respectivamente em relação ao tratamento sem palha de azevém. Uma das causas da redução do rendimento de grãos em função do aumento da quantidade de palha pode ser a liberação de substâncias tóxicas pela decomposição da palha. Os resultados obtidos estão de acordo com as afirmações de PONNAMPERUMA (1965), CANNELL \& LYNCH (1984) e (WATANABE, 1984).

O manejo da irrigação afetou o rendimento de grãos de arroz, constatando maior produtividade no manejo da água com drenagem, seguido pelo fluxo de superfície e o menor rendimento com lâmina estagnada (Tabela 1). O baixo rendimento de grãos no tratamento com lâmina estagnada pode ser atribuído à presença de ácidos orgânicos. Esses ácidos são liberados para a solução do solo quando há decomposição anaeróbia da palha. Este comportamento não foi constatado quando uma lâmina de água de 10 $\mathrm{mm}$ percolou pelo solo ou circulou na superfície do solo. Assim, alternativas de manejo da água de irrigação e da quantidade de palha de azevém, (intensificando o pastoreio dos animais antes de inundar o solo para implantar o sistema mix de pré-germinado) são práticas de manejo que podem ser utilizadas para reduzir os possíveis efeitos de substâncias tóxicas produzidas pelo processo de decomposição anaeróbia da palha de azevém, o que possibilita o aumento do rendimento de grãos na cultura do arroz irrigado.

O manejo da água com fluxo de superfície proporcionou rendimento de grãos intermediário entre os manejos da água com drenagem e lâmina estagnada. O tratamento com fluxo de superfície é semelhante ao manejo da água utilizado na inundação contínua, com água circulando pelos quadros. Conforme PANDE \& MITRA (1970); DOTTO et al. (1990); STONE et al. (1990); FORNASIERI FILHO \& FORNASIERI (1993)a inundação contínua do arroz irrigado propicia maior rendimento, favorece a absorção de nutrientes e o controle de plantas daninhas. Os mesmos autores concluíram que a inundação contínua na fase reprodutiva propicia maior rendimento de arroz, por favorecer o perfilhamento e a obtenção de um maior número de grãos por panículas, bem como a massa de grãos, sendo menos eficiente no uso da água em comparação com a inundação intermitente, (BARRETO \& ROJAS, 1987)

Na tabela 1, constata-se menor número de panículas e menor acúmulo de massa seca no tratamento com lâmina estagnada quando comparado com os tratamentos com drenagem e com fluxo de superfície, refletindo-se no menor rendimento de grãos. Pelos resultados obtidos, constata-se que, para o sistema mix de pré-germinado, o manejo da irrigação e a quantidade de palha de azevém no momento da implantação do arroz são decisivos para a viabilização do sistema. Assim, o manejo da cobertura de azevém para a implantação do sistema pré-germinado, de modo a não impedir o estabelecimento inicial das plântulas, associado ao manejo da irrigação, propiciando bom perfilhamento e produção de massa seca são procedimentos de manejo importantes para alcançar bom potencial de produção de grãos.

O maior rendimento de grãos foi obtido, no tratamento de manejo da irrigação com drenagem interna no solo, como conseqüência do maior número de plantas estabelecidas, maior massa seca das plantas e maior número de panículas na colheita.

\section{CONCLUSÃO}

O cultivo do arroz irrigado no sistema mix de pré-germinado com drenagem de $10 \mathrm{~mm}$ de altura de lâmina de água por dia, proporciona maior rendimento de grão.

O aumento na quantidade de palha de azevém, na cultura do arroz irrigado no sistema de cultivo mix de pré-germinado, reduz linearmente o rendimento de grãos.

\section{REFERÊNCIAS BIBLIOGRÁFICAS}

AGRIANUAL 2001. Anuário da Agricultura Brasileira FND Consultoria e Comércio. São Paulo, 2001. 545p.

BARRETO, J.R.R.; ROJAS, P. Manejo de água y nitrogeno en arroz riego en el ville del cuaca. Acta Agronomica, Palmira, v.37,n.1, p.22-34, 1987. 
CANNELL, R.Q.; LYNCH J.M. Possible adverse effects of decomposing crop residues on plant growthp. In:

Organic matter and rice. Filipinas : International Rice Research Institute, 1984. p.455-475.

DOTTO, C.R.D.; RIGHES, A.A.; CARLESSO, R. Consumo de água e produtividade da cultura do arroz sob três sistemas de irrigação. In: CONGRESSO BRASILEIRO DE ENGENHARIA AGRÍCOLA, 19, 1990, Piracicaba. Anais... Piracicaba : SBEA, 1990. p.396-409.

FORNASIERI, F.D.; FORNASIERI, J.L. Manual da cultura do arroz. Jaboticabal : FUNEP, 1993. 221p.

HITE, C.D.; CHENG, S. Spatial characterization of hydrogeochemistry within a constructed fen, Greene County, Ohio. Ground Water, v.34 n.3 p.415-424, 1996.

PANDE, H.K. ; MITTRA, B.N. Response of lowland rice to varying levels of soil, water, and fertility management in different seasons. Agronomy Journal, Madison, v. 62, n.2, p.187-189, 1970 .
PONNAMPERUMA, F.M. Dynamic aspects of flooded soils and the nutrition of the rice plant. In: SYMPOSIUM OF THE INTERNATIONAL RICE RESEARCHE INSTITUTE. Baltimore, 1964. The mineral nutrition of the rice plant: Proceedings... Baltimore : IRRI, 1965. Cap. 18, p.295328 .

STRECK, E.V.; KAMPF, N.; KLAMT, E. Atualização da classificação taxonômica das unidades de mapeamento do levantamento de reconhecimento dos solos do estado do Rio Grande do Sul. Informativo EMATER, v.16, n.9, p.1-5, 1999.

STONE, L.F.; MOREIRA, J.A.A.; SILVEIRA FILHO, A. Manejo de água na cultura do arroz: consumo, ocorrência de plantas daninhas, absorção de nutrientes e características produtivas. Pesquisa Agropecuária Brasileira, Brasília, v.25 n.3 p.323$337,1990$.

WATANABE, I. Anaerobic decomposition of organic matter in flooded rice soils. In: IRRI. Organic matter and rice research institute. Filipinas : IRRI, 1984. p.235-258. 